\title{
Children Attending Addiction Treatment Services in Dublin, 1990-1999
}

\author{
Bobby P. Smyth Mary O'Brien \\ Drug Misuse Research Division, Health Research Board, Dublin, Ireland
}

\section{Key Words}

Children · Adolescents - Substance misuse - Treatment • Heroin · Ireland

\begin{abstract}
In Europe, adolescent substance misuse increased during the 1990s. Ireland has among the highest rates of substance misuse among schoolchildren in Europe. We sought to describe the socio-demographic and drug misuse profile of children presenting to addiction treatment services in Dublin during the 1990s. Of the 9,874 individuals who sought addiction treatment, 1,953 (20\%) were aged less than 18 years. There was a sharp increase in the number of children after 1993. The main drug of abuse was an opiate in $48 \%$ of cases. Compared to adults, the children were more likely to be female and less likely to inject. As the decade progressed the proportion of girls increased, injecting was reported more frequently and there was a dramatic rise in heroin misuse. Child heroin users were more likely to be female and to be homeless compared to their adult counterparts. This study highlights the need for a dedicated service for child drug users in Dublin.
\end{abstract}

\section{Introduction}

There is growing international concern regarding substance misuse by children and adolescents. European data indicate that the prevalence of substance misuse among schoolchildren increased substantially in the early 1990s [1]. Within Europe, there is evidence of comparatively high rates of drug use among Irish and UK adolescents [2, $3]$. This is reflected in increases in the number of young people seeking treatment for drug misuse in Ireland. There were more than six times as many new patients under 21 years of age entering addiction treatment during the middle of the 1990s compared with 1990-1991 [4]. The majority of those presenting for treatment of drug misuse in Dublin reported that heroin was their principal drug of misuse [4]. Adolescents present with more complex patterns of drug use compared to their adult counterparts [5]. Internationally, there have been calls for specialist adolescent addiction services in view of the different needs of people in this age group [6-8]. In Ireland the National Children's Strategy has identified a need for such service development [9].

In 1990, the Health Research Board (HRB) established the Drug Treatment Reporting System. This covered the Greater Dublin area only until 1995, when it became the

\begin{tabular}{ll}
\hline KARGER & ( ) 2004 S. Karger AG, Basel \\
1022-6877/04/0102-0068\$21.00/0 \\
$\begin{array}{l}\text { Fax +4161306 1234 } \\
\begin{array}{l}\text { E-Mail karger@karger.ch } \\
\text { www.karger.com }\end{array}\end{array}$ & $\begin{array}{l}\text { Accessible online at: } \\
\text { www.karger.com/ear }\end{array}$
\end{tabular}

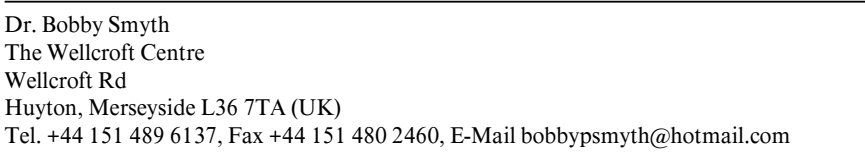


National Drug Treatment Reporting System (NDTRS). All agencies providing treatment or therapy for problem drug use were requested to complete a structured questionnaire on each client attending their service. Services providing only syringe exchange did not participate in this reporting system. Staff from the HRB maintained frequent contact with all treatment agencies to ensure compliance with the reporting system. Data were obtained on treatment contact details, socio-demographic information, problem drug use and risk behaviour. Names and other identifying information were not recorded in the database to ensure anonymity.

It has been proposed that a specialist addiction service be developed for children and adolescents in Dublin. We recognised that the NDTRS database could provide useful descriptive information on the adolescents who have been presenting to treatment services over the past decade in Dublin. Consequently, we sought to describe the sociodemographic and drug use profile of this group. Secondly, we anticipated that adolescents might present quite differently to adults, and therefore we decided to examine for these differences. Thirdly, we sought to explore for temporal changes in the profile of the adolescent drug user over the decade. As adolescent heroin users are the group of young drug users causing most concern, we looked specifically at this group, seeking to identify characteristics that distinguish them from adult heroin users.

\section{Method}

The database of the NDTRS was used in this study. Individuals were included if they made their first ever treatment contact to addiction services between January 1990 and December 1999. We confined the analysis to first treatment contacts in order to ensure that data on each adolescent was included only once. Only residents in the greater Dublin area were included. In Ireland, the Children Act 2001 defines a child as a person who is aged under 18 years. We used this definition in this study. We have attempted to avoid use of the poorly defined word 'adolescent' in subsequent paragraphs.

Pearson's $\chi^{2}$ test was used to examine associations between the categorical variables and age group. Odds ratios (OR) and their $95 \%$ confidence intervals (CI) were calculated to determine the direction and magnitude of the association. The Mantel-Haenszel $\chi^{2}$ test for linear trend was used to examine for the presence of significant temporal trends.

A small proportion of the data was missing for each of the variables examined. The proportion of missing data varied from $0.1 \%$ for the 'main drug' to $5.4 \%$ for 'injected in the past month'.

\section{Results}

During the 1990 s, 9,874 new patients presented to addiction services in Dublin seeking treatment and 1,953 (19.8\%) of these were children. Table 1 indicates that $28 \%$ of the children were aged between 10 and 15 years. The vast majority of children were living with their parents. The primary drug of misuse was an opiate in $48 \%$ of cases. Opiates, cannabis, volatile inhalants and ecstasy accounted for $93 \%$ of presentations by children. Other primary drugs of misuse included benzodiazepines $(2.2 \%)$, LSD $(2.2 \%)$, amphetamines $(0.4 \%)$ and cocaine $(0.3 \%)$.

Females were in the minority in both age groups. Compared to adults, females were over-represented among the children who attended treatment (table 1). In terms of accommodation, children were more likely to be living with parents or family of origin. More surprisingly, they were significantly more likely to be homeless compared to their adult counterparts. They were less likely to present with heroin or other opiate misuse, but more likely to identify cannabis as their main drug of misuse. The children were less likely to be using drugs on a daily basis and much less likely to report injecting.

Over the decade, a number of significant trends were identified among the children presenting for treatment (see table 2). The female to male ratio increased. Services encountered an increasing proportion of children who were using heroin and a decline in both cannabis and volatile inhalant use. In parallel with the rise in heroin misuse, it was observed that children seeking treatment were more likely to report daily drug use and more likely to have experience of injecting.

Children accounted for $13.3 \%$ of the 6,332 people who sought treatment for heroin use during the 1990s. The socio-demographic and drug misuse profiles of these children are shown in table 3 . This table also indicates that the children who used heroin differed from their adult counterparts in many respects. Females accounted for a relatively large proportion of the children, and homelessness was reported more frequently. Children were more likely to be smoking (i.e. chasing) heroin than injecting. Although the majority of child heroin users reported daily heroin use, they were less likely to be using heroin every day when compared to the adult group.

Table 4 demonstrates the changes that occurred in the profile of child heroin users over the decade. The number of children presenting for treatment rose sharply during the first eight years before falling back in 1998-1999. The gender profile changed significantly, with the proportion of females increasing sharply. Homelessness was encoun- 
Table 1. Comparison of adults and children seeking treatment for drug misuse in Dublin, 1990-1999

\begin{tabular}{|c|c|c|c|c|c|c|c|}
\hline \multirow[t]{2}{*}{ Variable } & \multicolumn{2}{|c|}{ Children } & \multicolumn{2}{|c|}{ Adults } & \multirow[t]{2}{*}{ OR } & \multirow[t]{2}{*}{$95 \% \mathrm{CI}$} & \multirow[t]{2}{*}{$\mathrm{p}$ value } \\
\hline & $\mathrm{n}$ & $\%$ & $\mathrm{n}$ & $\%$ & & & \\
\hline Total & 1,953 & & 7,921 & & & & \\
\hline \multicolumn{8}{|l|}{ Age, years } \\
\hline $10-12$ & 22 & 1.1 & NA & & & & \\
\hline $13-15$ & 527 & 27.0 & NA & & & & \\
\hline $16-17$ & 1,404 & 71.9 & NA & & & & \\
\hline \multicolumn{8}{|l|}{ Gender } \\
\hline Male & 1,339 & 69.1 & 6,011 & 76.4 & 1.0 & & \\
\hline Female & 599 & 30.9 & 1,856 & 23.6 & 1.45 & $1.30-1.62$ & $<0.001$ \\
\hline \multicolumn{8}{|l|}{ Accommodation } \\
\hline With parents/family & 1,653 & 86.1 & 5,396 & 71.1 & 2.50 & $2.17-2.88$ & $<0.001$ \\
\hline Other accommodation ${ }^{1}$ & 142 & 7.4 & 2,047 & 27.0 & 0.22 & $0.18-0.26$ & $<0.001$ \\
\hline Homeless/temporary & 125 & 6.5 & 147 & 1.9 & 3.34 & $2.60-4.30$ & $<0.001$ \\
\hline \multicolumn{8}{|l|}{ Main drug } \\
\hline Heroin & 841 & 43.2 & 5,491 & 69.3 & 0.35 & $0.31-0.38$ & $<0.001$ \\
\hline Other opiate & 96 & 4.9 & 989 & 12.5 & 0.35 & $0.28-0.44$ & $<0.001$ \\
\hline Cannabis & 644 & 33.1 & 789 & 10.0 & 4.33 & $3.84-4.89$ & $<0.001$ \\
\hline Volatile inhalants & 140 & 7.2 & 18 & 0.2 & 33.9 & $20.2-57.3$ & $<0.001$ \\
\hline Ecstasy & 96 & 4.9 & 287 & 3.6 & 1.35 & $1.05-1.72$ & 0.01 \\
\hline Other & 136 & 7.0 & 337 & 4.3 & 1.68 & $1.36-2.08$ & $<0.001$ \\
\hline \multicolumn{8}{|l|}{ Frequency of drug use } \\
\hline Every day & 847 & 45.2 & 5,370 & 71.5 & 0.33 & $0.29-0.36$ & $<0.001$ \\
\hline Less than daily & 1,028 & 54.8 & 2,136 & 28.5 & 1.0 & & \\
\hline \multicolumn{8}{|l|}{ Injected in past month } \\
\hline Yes & 266 & 14.1 & 2,754 & 36.8 & 0.28 & $0.25-0.33$ & $<0.001$ \\
\hline No & 1,623 & 85.9 & 4,733 & 63.2 & 1.0 & & \\
\hline \multicolumn{8}{|l|}{ Injected ever } \\
\hline Yes & 406 & 21.6 & 4,276 & 55.6 & 0.22 & $0.19-0.25$ & $<0.001$ \\
\hline No & 1,473 & 78.4 & 3,411 & 44.4 & 1.0 & & \\
\hline
\end{tabular}

$\mathrm{OR}=$ Odds ratio $\mathrm{CI}=$ confidence interval.

1 Examples included living with spouse, partner or friend.

tered more frequently as the decade progressed, but this trend did not quite reach statistical significance. Looking at the decade as a whole, there was no significant trend in terms of route of heroin use. However, this statistical fact conceals some important observed changes. A post hoc analysis reveals a very significant decline in injecting over the first eight years $\left(\chi^{2}\right.$ for linear trend $=17.6 ; p<0.001$ ). This pattern reversed dramatically in 1998-1999, during which children were much more likely to report injecting compared to their counterparts in 1996-1997 (OR $=2.1$; $95 \% \mathrm{CI}=1.4-3.2 ; \mathrm{p}<0.001)$. Over the decade, children reported progressively earlier ages of initiation of heroin use. There was evidence that children were delaying entry into treatment as the proportion of children presenting to addiction services within a year of first heroin use significantly diminished.

\section{Discussion}

This study demonstrates that very substantial numbers of children presented to addiction services in Dublin seeking treatment during the 1990s. Ireland has the youngest mean age of treated drug use in Europe [10]. Our findings indicate that, between 1994 and 1999, an average of 11 children per month presented for treatment of heroin misuse in Dublin. In view of the particular challenges and difficulties of treating drug misuse in this age group, children therefore generate a substantial proportion of the workload of addiction services in Dublin [6].

Compared to their adult counterparts, children who sought treatment were more likely to be female, especially where heroin was the main drug of misuse. Although the number of boys exceeded the number of girls throughout 
Table 2. Temporal trends in children seeking treatment for drug misuse in Dublin, 1990-1999

\begin{tabular}{|c|c|c|c|c|c|c|c|c|c|c|c|c|}
\hline & \multicolumn{2}{|c|}{ 1990-1991 } & \multicolumn{2}{|c|}{ 1992-1993 } & \multicolumn{2}{|c|}{ 1994-1995 } & \multicolumn{2}{|c|}{ 1996-1997 } & \multicolumn{2}{|c|}{ 1998-1999 } & \multirow[t]{2}{*}{$\chi^{2}$} & \multirow[t]{2}{*}{ p value } \\
\hline & $\mathrm{n}$ & $\%$ & $\mathrm{n}$ & $\%$ & $\mathrm{n}$ & $\%$ & $\mathrm{n}$ & $\%$ & $\mathrm{n}$ & $\%$ & & \\
\hline Total & 215 & & 327 & & 558 & & 555 & & 298 & & & \\
\hline \multicolumn{13}{|l|}{ Age, years } \\
\hline $11-15$ & 86 & 40 & 103 & 31 & 151 & 27 & 129 & 23 & 79 & 27 & & \\
\hline $16-17$ & 129 & 60 & 224 & 69 & 407 & 73 & 426 & 77 & 218 & 73 & 16.7 & $<0.001$ \\
\hline \multicolumn{13}{|l|}{ Gender } \\
\hline Female & 65 & 30 & 95 & 29 & 126 & 23 & 207 & 38 & 106 & 36 & & \\
\hline Male & 150 & 70 & 232 & 71 & 427 & 77 & 339 & 62 & 191 & 64 & 9.4 & 0.002 \\
\hline \multicolumn{13}{|l|}{ Accommodation } \\
\hline Homeless & 10 & 5 & 29 & 9 & 35 & 6 & 31 & 6 & 20 & 7 & & \\
\hline Not homeless & 202 & 95 & 293 & 91 & 510 & 94 & 514 & 94 & 276 & 93 & 0.07 & 0.79 \\
\hline \multicolumn{13}{|l|}{ Main drug } \\
\hline Heroin & 10 & 5 & 46 & 14 & 252 & 45 & 376 & 68 & 157 & 53 & 294 & $<0.001$ \\
\hline Other opiate & 30 & 14 & 25 & 8 & 25 & 4 & 8 & 1 & 8 & 3 & 48.4 & $<0.001$ \\
\hline Cannabis & 103 & 48 & 135 & 41 & 188 & 34 & 123 & 22 & 95 & 32 & 11.1 & $<0.001$ \\
\hline Volatile inhalants & 48 & 22 & 43 & 13 & 22 & 4 & 11 & 2 & 16 & 5 & 81.2 & $<0.001$ \\
\hline Ecstasy & 1 & 0.5 & 30 & 9 & 33 & 6 & 24 & 4 & 8 & 3 & 0.97 & 0.33 \\
\hline Other & 23 & 11 & 48 & 15 & 38 & 7 & 13 & 2 & 14 & 5 & & \\
\hline \multicolumn{13}{|c|}{ Frequency of use of main drug } \\
\hline Daily & 65 & 31 & 94 & 30 & 231 & 42 & 302 & 58 & 155 & 55 & & \\
\hline Les than once/day & 142 & 69 & 222 & 70 & 316 & 58 & 223 & 42 & 125 & 45 & 76.8 & $<0.001$ \\
\hline \multicolumn{13}{|l|}{ Lifetime injecting } \\
\hline Injected & 29 & 14 & 50 & 16 & 115 & 22 & 123 & 23 & 89 & 31 & & \\
\hline Never injected & 173 & 86 & 270 & 84 & 419 & 78 & 413 & 77 & 198 & 69 & 25.9 & $<0.001$ \\
\hline \multicolumn{13}{|l|}{ Injected in past month } \\
\hline Yes & 19 & 9 & 32 & 10 & 71 & 13 & 85 & 16 & 59 & 21 & 34.3 & $<0.001$ \\
\hline No & 183 & 91 & 288 & 90 & 463 & 87 & 453 & 84 & 227 & 79 & & \\
\hline
\end{tabular}

the study period, the proportion of females increased as the decade proceeded. Drug misuse, particularly heroin use, is associated with criminality, increased risk behaviours, unplanned pregnancy and poorer physical and psychological well-being [7]. Consequently, the increase in the number of young girls presenting with serious drug misuse has implications for many services in addition to addiction treatment facilities. Those who plan provision of obstetric and neonatal services, social services, education and prison services must prepare to meet the consequences of this worrying trend.

The majority of both adult and child drug users were living with their family of origin. However, in view of their younger age and earlier developmental stage, the ongoing close links with family are particularly important and relevant to the treatment of children. The principal psychological therapies offered by addiction services in Dublin fall into the categories of individual therapy or group therapy. Work with families and parents generally accounts for only a small proportion of therapeutic input with adults. By contrast, the involvement of families in the treatment of drug-addicted children is viewed as essential by international bodies such as the American Academy of Child and Adolescent Psychiatry [11]. A number of studies have demonstrated the superiority of family therapy approaches over other treatments when dealing with child and adolescent drug users [12, 13]. Consequently, services in Dublin dealing with increasing numbers of children have had to create new treatment programs for this age group, developing new skills to meet the rapidly evolving problem [6].

Although most children were living with parents, a substantial and growing minority were homeless. Children were more likely than adults to be homeless. Homeless youths are probably the subgroup of patients with the greatest range of problems, but they are the most difficult group to reach and to retain in treatment [14]. Consequently, the recent provision in Dublin of a service which is dedicated to meet the needs of this group is timely. 
Table 3. Comparison of adults and children seeking treatment for heroin misuse in Dublin, 1990-1999

\begin{tabular}{|c|c|c|c|c|c|c|c|}
\hline \multirow[t]{2}{*}{ Variable } & \multicolumn{2}{|c|}{ Children } & \multicolumn{2}{|l|}{ Adults } & \multirow[t]{2}{*}{ OR } & \multirow[t]{2}{*}{$95 \% \mathrm{CI}$} & \multirow[t]{2}{*}{$\mathrm{p}$ value } \\
\hline & $\mathrm{n}$ & $\%$ & $\mathrm{n}$ & $\%$ & & & \\
\hline Total & 841 & & 5,491 & & & & \\
\hline \multicolumn{8}{|l|}{ Age, years } \\
\hline $10-12$ & 0 & 0 & N/A & & & & \\
\hline $13-15$ & 112 & 13.3 & N/A & & & & \\
\hline $16-17$ & 729 & 86.7 & N/A & & & & \\
\hline \multicolumn{8}{|l|}{ Gender } \\
\hline Male & 553 & 64.1 & 4,014 & 73.7 & 1.0 & & \\
\hline Female & 298 & 35.9 & 1,431 & 26.3 & 1.57 & $1.34-1.83$ & $<0.001$ \\
\hline \multicolumn{8}{|l|}{ Accommodation } \\
\hline With parents & 716 & 87,2 & 3.795 & 72.0 & 2.65 & $2.13-3.30$ & $<0.001$ \\
\hline Other accomodation & 65 & 7.9 & 1,389 & 26.4 & 0.24 & $0.18-0.31$ & $>0.001$ \\
\hline Homeless/temporary & 40 & 4.9 & 85 & 1.6 & 3.12 & $2.09-4.66$ & $<0.001$ \\
\hline \multicolumn{8}{|l|}{ Main route of use $\mathrm{e}^{1}$} \\
\hline Injecting & 275 & 33.2 & 2,889 & 53.5 & 0.43 & $0.37-0.50$ & $<0.001$ \\
\hline Smoking & 553 & 66.8 & 2,506 & 46.5 & 1.0 & & \\
\hline \multicolumn{8}{|l|}{ Frequency of use } \\
\hline Daily & 593 & 72.8 & 4,011 & 77.3 & 0.78 & $0.66-0.93$ & 0.005 \\
\hline Less than daily & 222 & 27.2 & 1,179 & 22.7 & 1.0 & & \\
\hline
\end{tabular}

$\mathrm{OR}=$ Odds ratio $\mathrm{CI}=$ confidence interval.

1 Five patients reported heroin use via sniffing/snorting.

Table 4. Temporal trends in children seeking treatment for heroin misuse in Dublin, 1990-1999

\begin{tabular}{|c|c|c|c|c|c|c|c|c|c|c|c|c|}
\hline & \multicolumn{2}{|c|}{ 1990-1991 } & \multicolumn{2}{|c|}{ 1992-1993 } & \multicolumn{2}{|c|}{ 1994-1995 } & \multicolumn{2}{|c|}{ 1996-1997 } & \multicolumn{2}{|c|}{ 1998-1999 } & \multirow[t]{2}{*}{$\chi^{2}$} & \multirow[t]{2}{*}{$\mathrm{p}$ value } \\
\hline & $\mathrm{n}$ & $\%$ & $\mathrm{n}$ & $\%$ & $\mathrm{n}$ & $\%$ & $\mathrm{n}$ & $\%$ & $\mathrm{n}$ & $\%$ & & \\
\hline Total & 10 & & 46 & & 252 & & 376 & & 157 & & & \\
\hline \multicolumn{13}{|l|}{ Age, years } \\
\hline $13-15$ & 0 & 0 & 3 & 7 & 33 & 13 & 61 & 16 & 15 & 10 & & \\
\hline $16-17$ & 10 & 100 & 43 & 93 & 219 & 87 & 315 & 84 & 142 & 90 & 0.33 & 0.56 \\
\hline \multicolumn{13}{|l|}{ Gender } \\
\hline Female & 3 & 30 & 11 & 24 & 61 & 24 & 156 & 42 & 67 & 43 & & \\
\hline Male & 7 & 70 & 35 & 76 & 188 & 76 & 214 & 58 & 89 & 57 & 18.9 & $<0.001$ \\
\hline \multicolumn{13}{|l|}{ Accommodation } \\
\hline Homeless & 0 & 0 & 1 & 2 & 11 & 5 & 15 & 4 & 13 & 8 & & \\
\hline Not homeless & 10 & 100 & 44 & 98 & 233 & 95 & 352 & 96 & 142 & 92 & 3.6 & 0.06 \\
\hline \multicolumn{13}{|l|}{ Route of use } \\
\hline Injecting & 5 & 56 & 26 & 59 & 80 & 32 & 96 & 26 & 68 & 43 & & \\
\hline Smoking & 4 & 44 & 18 & 41 & 168 & 68 & 274 & 74 & 89 & 57 & 0.83 & 0.36 \\
\hline \multicolumn{13}{|l|}{ Frequency of heroin use } \\
\hline Daily & 7 & 87 & 28 & 62 & 173 & 69 & 271 & 75 & 114 & 76 & & \\
\hline Less than once/day & 1 & 13 & 17 & 38 & 77 & 31 & 91 & 25 & 36 & 24 & 3.3 & 0.07 \\
\hline \multicolumn{13}{|l|}{ Age of first heroin use } \\
\hline $12-14$ & 1 & 10 & 2 & 5 & 39 & 16 & 93 & 26 & 55 & 36 & & \\
\hline $15-17$ & 9 & 90 & 42 & 95 & 209 & 84 & 271 & 74 & 98 & 64 & 31.3 & $<0.001$ \\
\hline \multicolumn{13}{|l|}{ Duration of heroin use } \\
\hline 1 year & 8 & 80 & 33 & 75 & 190 & 78 & 252 & 70 & 85 & 57 & & \\
\hline$>1$ year & 2 & 20 & 11 & 25 & 54 & 22 & 108 & 30 & 64 & 43 & 16.2 & $<0.001$ \\
\hline
\end{tabular}

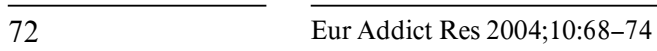


This study describes drug misuse among children who attend for treatment and it emerged that heroin accounted for almost half of all presentations. The profile of drug use described in population samples of Irish schoolchildren is very different. The 1995 ESPAD survey of 15and 16 -year-olds found that $37 \%$ reported a lifetime prevalence of cannabis use compared to $2 \%$ reporting a lifetime prevalence of heroin use [2]. In 1998 over 6,000 schoolchildren, aged from 10 to 18 years, from Dublin and two neighbouring counties were included in a survey. This study found lifetime prevalences of $21 \%$ for cannabis and $1 \%$ for heroin [15]. These surveys indicate that children are about 20 times more likely to use cannabis than heroin. Of the drugs examined in these two surveys, heroin was the drug used by the lowest proportion of children. Taking an overview of the two surveys, compared to rates of heroin use, cocaine was used by 1.5 times as many children, amphetamines about twice as frequently, ecstasy and hypnotics were each used about 3 times more often and hallucinogens about 5 times more frequently. Schoolbased surveys are particularly likely to underestimate the population prevalence of drugs such as heroin, as children who use heroin are more likely to play truant or to be excluded from schools. Within the population of children who use drugs, it is clear that heroin users are most likely to attend treatment and users of other substances are correspondingly under-represented among the treatment clinic attenders. The factors determining which child drug users attend for treatment are many and varied. These factors include the perceived (and actual) harm associated with use of various substances by the children themselves, their families, the community, doctors and the criminal justice system. Another factor is the perceived usefulness and appropriateness of the current treatment services. Kaminer [16] has argued that only a small proportion of those children who need, and who would gain benefit from, treatment actually receive it. These same factors make it impossible to draw firm conclusions about drug misuse at the population levels based on the type of treatment data reported in this study.

We observed a sustained rise in the number of children presenting for treatment of heroin misuse during the first eight years of the decade, while numbers reduced in 1998 and 1999. At the population level, there is some evidence that the pattern of escalating drug use seen in the early 1990s began to plateau at the end of the decade. The 1999 ESPAD study of 15- and 16-year-olds found a reduction in the lifetime prevalence of cannabis, LSD and ecstasy [17]. The lifetime experience of heroin and cocaine remained static, both at $2 \%$.

Children Attending Addiction Treatment

Services in Dublin
Our findings demonstrate some more worrying trends, particularly in relation to heroin use. Among the child heroin users, our data indicate that the age of initiation into heroin use dropped steadily over the decade and the delay before entering treatment increased. The increase in the proportion of injectors after 1997 is also a source of concern.

Unfortunately, the level of drug use among children in Dublin is a very substantial problem. Over the last decade large, and growing, numbers of people under the age of 18 years presented to addiction services. In addition to the actual rise in numbers, the type of problem with which children presented increased in severity and complexity. Heroin use, injecting and homelessness were all encountered with greater frequency among these children. Although girls remained in the minority, the proportion of girls rose steadily. Addiction services in Dublin were established to treat adult patients. These services have responded to the challenges posed by the presentation of large numbers of children by developing some age-specific programs. However, these have been insufficient to meet the need and access to them is geographically limited. Consequently, the fact that this issue has been specifically identified as a priority in the 2000 National Children's Strategy is timely and to be welcomed. The development of services to meet the specific needs of children should greatly improve accessibility and yield better outcomes $[7,16,18]$.

Eur Addict Res 2004;10:68-74 


\section{References}

1 European Monitoring Centre for Drugs and Drug Addiction: Annual report on the state of drugs problems in the European Union 1995. Lisbon, EMCDDA, 1996.

2 Hibell B, Andersson B, Bjarnason T, Kokkevi A, Morgan M, Narusk A: The 1995 ESPAD report: The European School Survey Project on Alcohol and Other Drugs. Alcohol and other drug use among students in 26 European countries. Stockholm, The Swedish Council for Alcohol and other Drugs (CAN) and Strasbourg, Council of Europe, Pompidou Group, 1997.

3 McArdle P, Wiegersma A, Gilvarry E, McCarthy S, Fitzgerald M, Kolte B, Brinkley A, Blom M, Stoeckel I, Pierolini A, Michels I, Johnson $\mathrm{R}$, Quensel S: International variations in youth drug use: The effect of individual behaviours, peer and family influences, and geographical location. Eur Addict Res 2000;6:163-169.

4 Smyth BP, O'Brien M, Barry J: Trends in treated opiate misuse in Dublin: The emergence of chasing the dragon. Addiction 2000; 95:1217-1223.

5 Parker H, Measham F: Pick'n'mix: Changing patterns of illicit drug use amongst 1990s adolescents. Drugs Educ Prev Policy 1994;1:5-14.

6 Keenan E: Treatment challenges in adolescent drug users. Health Gain 1999;3:3-6.
7 Gilvarry E: Substance abuse in young people. J Child Psychol Psychiatry 2000;41:55-80.

8 Health Advisory Service: The Substance of Young Needs: Review 2001. London, Health Advisory Service, 2001.

9 The National Children's Strategy. Our Children - Their Lives. Dublin, Government Publications, 2000

10 European Monitoring Centre for Drugs and Drug Addiction: Extended annual report on the state of the drugs problem in the European Union 1999. Lisbon, EMCDDA, 1999.

11 Bubstein O, and the Work Group on Quality Issues of the AACAP: Summary of practice parameters for assessment and treatment of children and adolescents with substance use disorders. J Am Acad Child Adolesc Psychiatry 1998;37:122-126.

12 Joaning H, Quinn T, Mullen R: Treating adolescent drug abuse: A comparison of family systems therapy, group therapy and family drug education. J Marital Fam Therapy 1992;18: 345-356.

13 Lewis R, Piercy F, Sprenkle D, Trepper T: Family-based interventions and community networking for helping drug abusing adolescents. The impact of near and far environments. J Addict Res 1990;50:82-95.
14 Unger JB, Kipke MD, Simon TR, Montgomery SB, Johnson CJ: Homeless youths and young adults in Los Angeles: Prevalence of mental health problems and relationship between mental health and substance abuse disorders. Am J Community Psychol 1997;25:371-394.

15 Rhatigan A, Shelley E: Health Behaviours of School Pupils in the Eastern Health Board. Dublin, Eastern Health Board, 1999.

16 Kaminer Y: Adolescent substance abuse treatment: Where do we go from here. Psychiatr Serv 2001;52:147-149.

17 Hibell B, Andersson B, Ahlstrom S, Balakireva O, Bjarnason T, Kokkevi A, Morgan M: The 1999 ESPAD Report. The European School Survey on Alcohol and Other Drugs. Alcohol and other drugs use among students in 30 European countries. Stockholm, The Swedish Council for Information on Alcohol and other Drugs, and Strasbourg, Council of Europe, Pompidou Group, 2001.

18 Hser YI, Grella CE, Hubbard RL, Hsieh SC, Fletcher BW, Brown BS, Anglin MD: An evaluation of drug treatments for adolescents in 4 US cities. Arch Gen Psychiatry 2001;58:689695. 